\title{
R3 - Avaliação de antígenos de sífilis para utilização em testes rápidos
}

Michel Vergne Sucupira ${ }^{1 *}$; Rafaela Lopes Diniz ${ }^{1}$; Aline Rodrigues Bernardo; Edimilson Domingos da Silva ${ }^{1}$.

\section{1 - Bio-Manguinhos/FIOCRUZ}

\section{Introdução:}

O diagnóstico rápido para Sífilis na saúde pública é uma necessidade urgente diante da escalada alarmante da doença na população brasileira. $\mathrm{O}$ atendimento e encaminhamento do paciente junto com seu (a) parceiro (a) diante de um diagnóstico positivo passa a ser imediato, impedindo a disseminação e agravamento da doença. Antígenos de origem nacional estão sendo desenvolvidos para a utilização em testes rápidos, com vistas à viabilização econômica do teste, com a diminuição do custo total e da dependência de fornecedores externos.

\section{Objetivo:}

Avaliar o desempenho de antígenos produzidos no Brasil para a detecção de anticorpos treponêmicos para sífilis e padronizar o teste às amostras brasileiras.

\section{Metodologia:}

Foi montado um algoritmo com diferentes concentrações de antígenos, diferentes membranas de nitrocelulose e diferentes formulações de tampões de corrida para execução dos testes. Os antígenos foram impregnados nas membranas de nitrocelulose e montados na plataforma de duplo percurso (DPP ${ }^{\circledast}$ ) para a avaliação do desempenho frente a um painel de amostras brasileiras positivas e negativas. Amostras positivas para outras doenças também foram utilizadas para verificação de possíveis reações cruzadas. Nesta plataforma apenas $5 \mu$ são necessários para a detecção dos anticorpos, seguidos de 2 gotas de tampão de corrida. A revelação da reação foi feita através do carreamento do conjugado Ouro/Ptn A por 4 gotas do tampão.

\section{Resultados:}

Resultados preliminares demonstraram que 1 entre as 4 proteínas avaliadas apresentou maior potencial para utilização em teste rápido de fluxo lateral em plataforma de duplo percurso. A avaliação dos resultados mostrou grande concordância com os resultados obtidos com testes de referência comerciais. 


\section{Conclusão:}

Proteínas desenvolvidas para diagnóstico de Sífilis no país apresentaram um grande potencial para utilização em teste rápido em plataforma de duplo percurso. A avaliação em plataformas mais simples será considerada posteriormente como forma de diminuir ainda mais o custo total de fabricação destes testes.

Palavras-Chave: teste rápido, Sífilis 